\title{
VI.
}

\section{Die Lymplibalnen der Membrana Descemeti (I) und ihr Zusammenhang mit der Hornhaut (II).}

Zugleich ein Beitrag zur Kenntniss der anastomosirenden Hornhantzellen (Virchow), und ihrer Mündungen an der Endothelffäche.

Von Dr. Otto Preiss in Hamburg.

(Hierzu Taf. II - IV.)

\section{I.}

In einer früheren Abhandlung ${ }^{1}$ ), auf welche hier öfters verwiesen werden muss, waren einige Einrichtungen an der Endothelschicht der hinteren Hornhautwand und an deren unmittelbarer Unterlage beschrieben worden, deren eingehendere Deutungen damals verschoben wurden; es wird jedoch aus der Darstellung hervorgegangen sein, dass jene Beobachtungen auf den Nachweis von Lymphbahnen gerichtet waren, welche unmittelbar mit der vorderen Kammer communicirten. Von den dort gewonnenen Resultaten, von denen ich hoffen darf, dass sie im Verlaufe dieser Abhandlung eine wesentlich festere Grundlage erhalten werden, betone ich namentlich das eine, dass die Kernmembranen der Endothelzellen mit den Zwischenräumen der Zellen und unter einander anastomosirten. Diesem Punkte werden wir noch ganz besondere Aufmerksamkeit schenken. - Auch gaben dort deutliche Präparate darüber Aufschluss, dass unmittelbar unter den Endothelzellen eine Schicht jener weissen anastomosirenden Gebilde (Saftkanälchen v. Reckling hau sen's) vorbanden sei (l. c. Taf. VIII. Figg. 14, 15), und es konnte am Rissrande des Endothelhäutchens der Uebergang eines von den weissen Figuren sich erhebenden Fortsatzes oder Röhrchens zu Zellenzwischenräumen und Kernmembranen gesehen werden (Fig. 10 l. c.). - Dass diese ganze Einrichtung der Endothelschicht selbst und ihrer unmittelbaren Unter-

1) Dieses Archiv Bd. 84. S. 334 ff. 
Virchow's Archio Bd, IXXXVIIT.

$22 \frac{2}{y}$

Tuf. II.
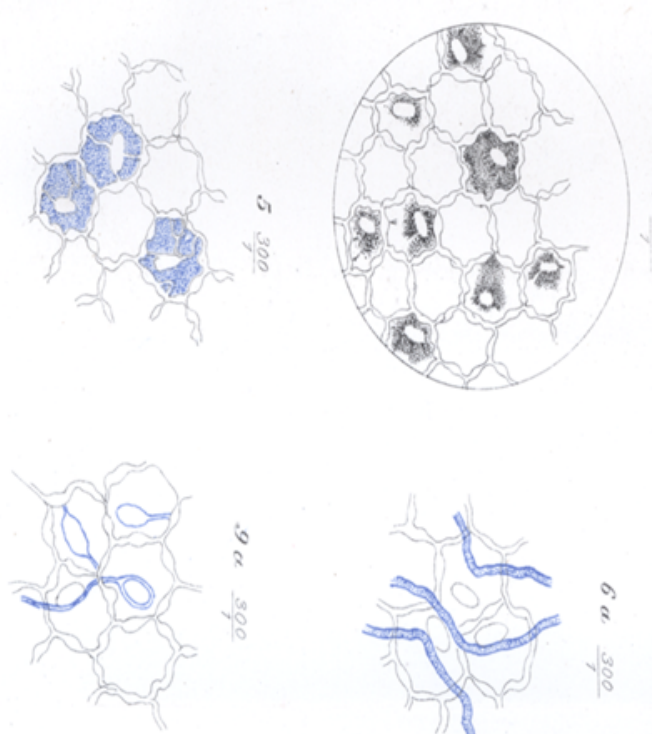

36.
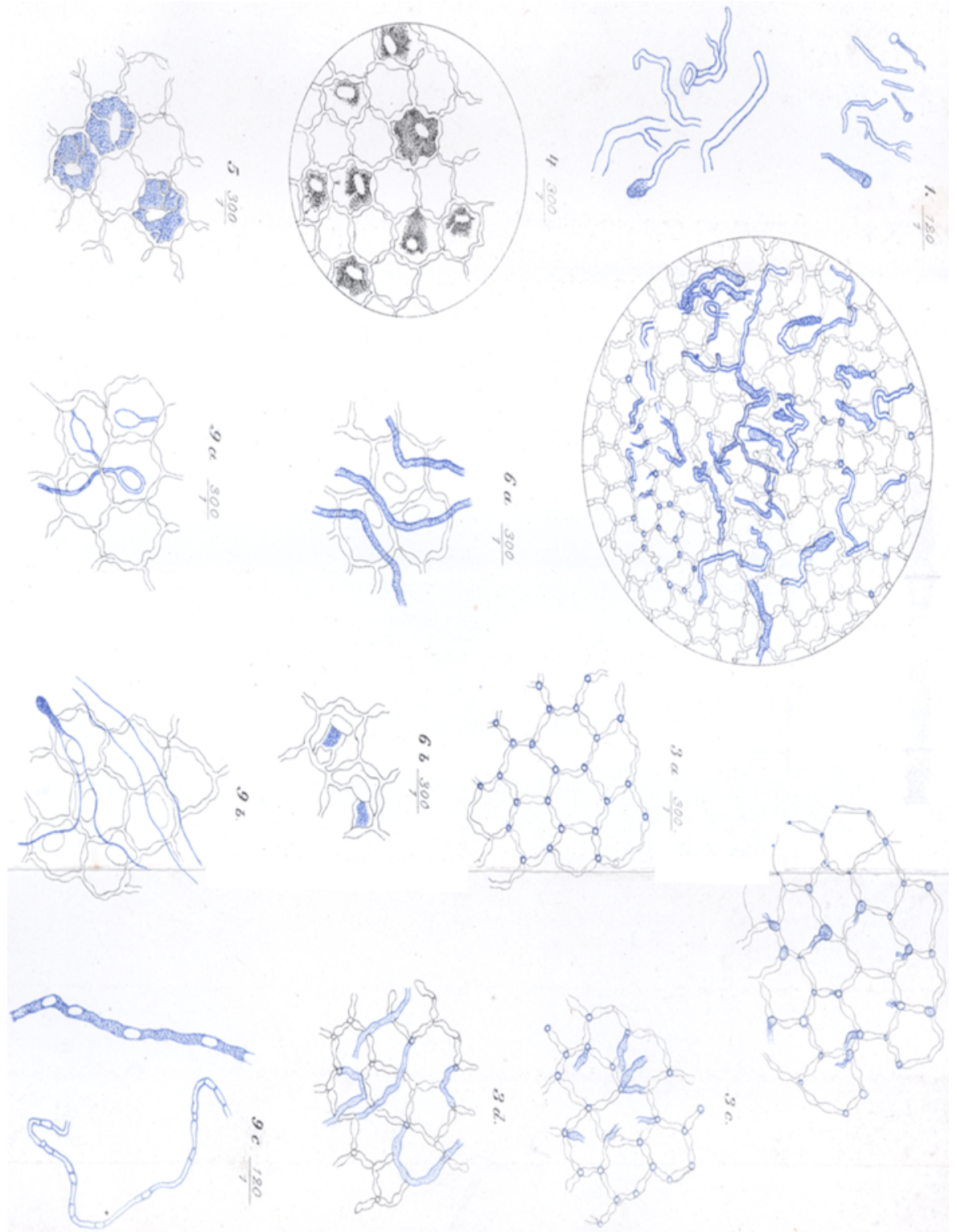

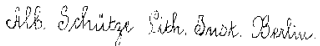



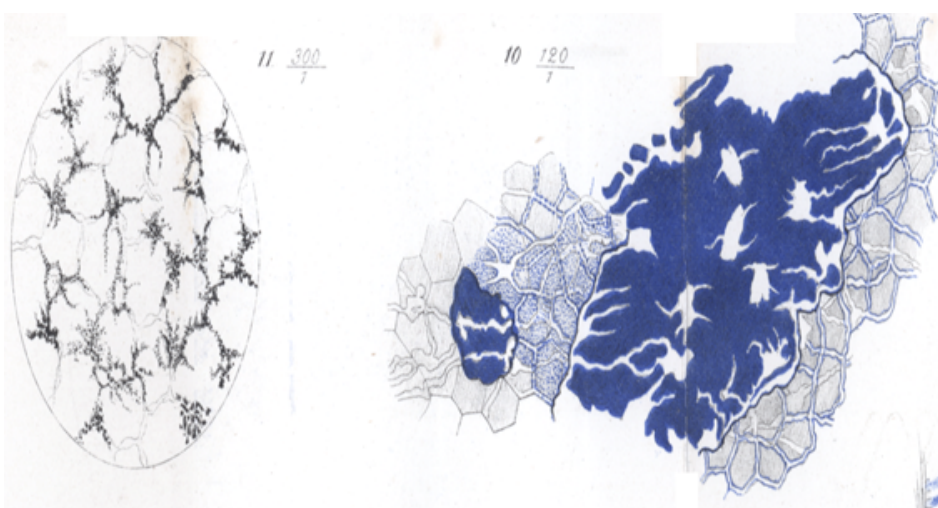

$13 \quad 180$
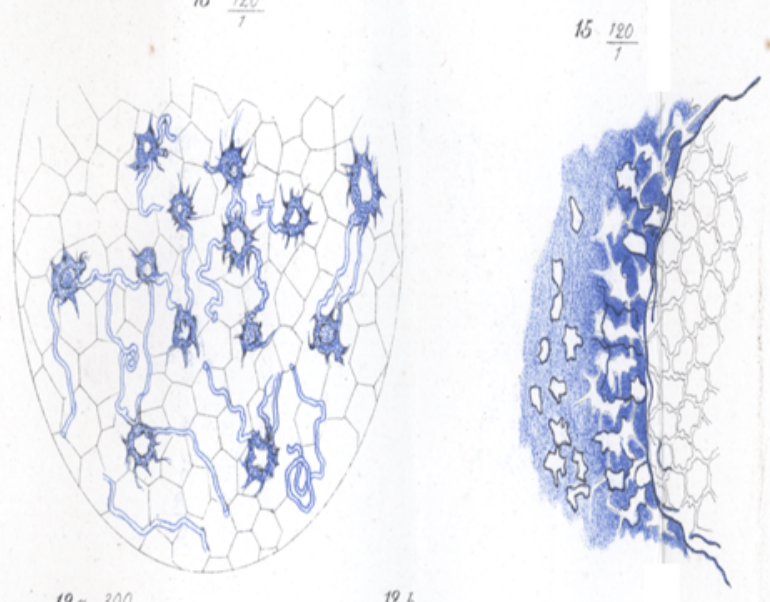

$$
\text { 12a. } \frac{300}{1}
$$

126

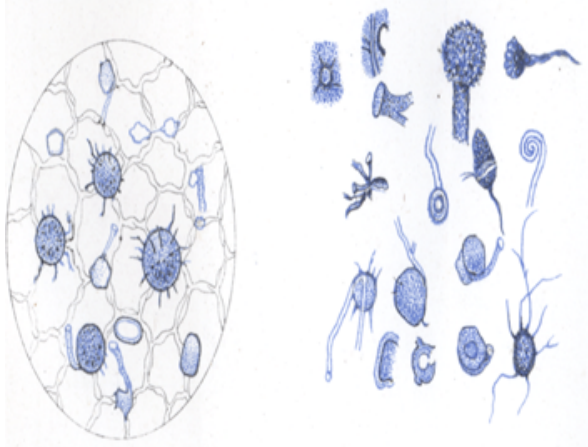

$14 \frac{120}{1}$

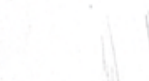

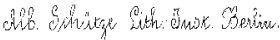


THüchow's Archio Bd. LXXXVII.
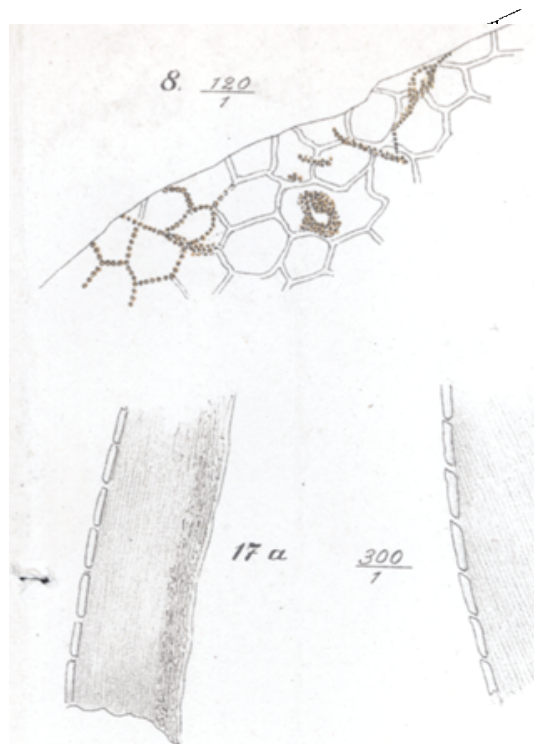

19.180

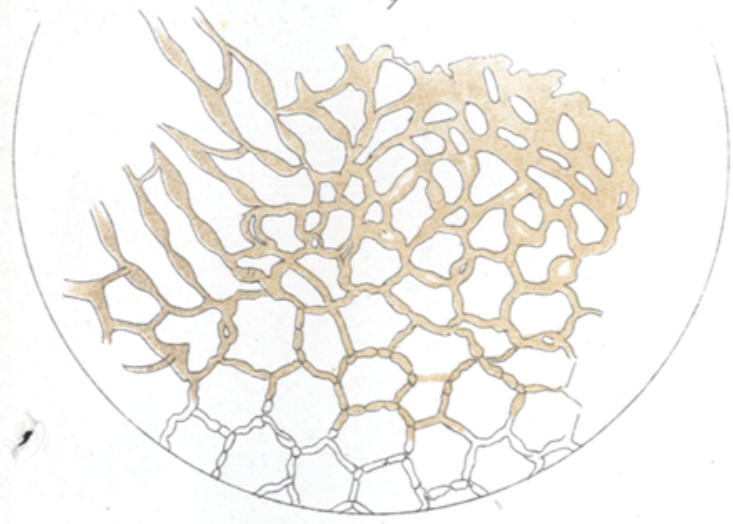

20. $\frac{180}{7}$
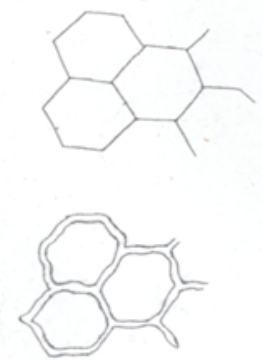

F. $\frac{780}{7}$

Taf: $L$

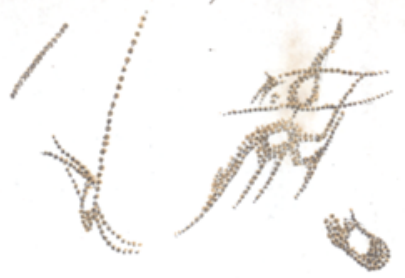

176

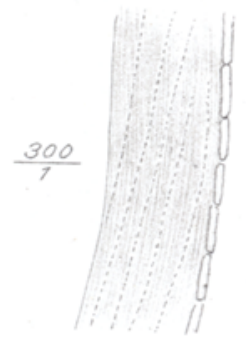

18.

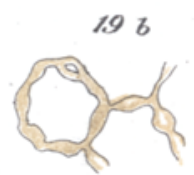

$19 a$.

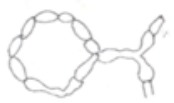

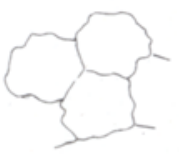

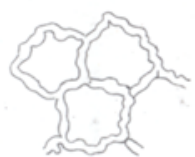

CHEB. Schintze Sith. Bnst. Berlive. 
lage angehörte, ging dort mit Sicherheit aus Querschnitten und aus Isolationspräparaten des zarten Endothelhäutchens hervor (Figg. 11 und 16 l. c.). -

In dieser Abhandlung soll die Vorstellung,--auf welchen Wegen Flüssigkeiten und körperliche Elemente zwischen der vorderen Kammer einerseits, und der Descemet'schen Haut und Hornhant andererseits verkebren können, noch wesentlich geklärt werden. Dabei wird über den Begriff der früher beschriebenen intercellulären Vacuolen, sowie über wahre und scheinbare Stomata für die bier untersuchte seröse Haut, wie ich hoffe, eine klarere Anschauung gewonnen werden. Die Untersuchung der Saftkanälchen war Anfangs nicht beabsichtigt, ergab sich jedoch dabei von selbst, und zwar fielen die Resultate in dem Sinne aus, welcher schon zum Theil in dem Zusatz zur Ueberschrift angedeutet wurde.

Hatte ich früher nach den zahlreichsten vergeblichen Versuchen die Hoffnung schon aufgeben müssen, dass es gelingen würde, ein deutlicheres Bild vorhandener Lymphgefässe an der Membrana Descemeti zu gewinnen, so muss ich jetzt einen Zufall, oder wenigstens einen Fall, an den früher nicht gedacht worden war, für das nachträgliche Gelingen verantwortlich machen. Indem ich damit beschäftigt war, mich über den vielbesprochenen Tröpfchenversuch an der Hornhaut zu orientiren, wurde auch gelegentlich ein Bulbus einem kräftigen Drucke ausgesetzt, um zu erfahren, ob sich Tröpfchen aus der Hornhaut pressen liessen. Die betreffende Hornhaut wurde dann noch der Berlinerblau-Reaction ausgesetzt, um mich von etwa eingetretenen Veränderungen am Endothel zu überzeugen. Auf diese Weise gelangte ich zur Darstellung eines Systems von Röhrchen, welches ich seinen Eigenschaften nach als Lymphröhrchensystem der Membrana Descemeti ansprechen muss. Theile dieses Systems sind an jedem auch ohne Druck hergesteliten Präparate zu erkennen, und bei meinen früheren Versuchen vielfach gesehen worden; nur bewirkt der stattgehabte Druck eine wesentlich vollkommenere Darstellung desselben, und erst wenn man vollkommenere Bilder gesehen hat, werden die unvollkommeneren verständlich. Aus der Darstellung wird sich, wie ich hoffe, von selbst ergeben, dass man von Kunstproducten hier nicht sprechen kann, und dass man die Wirkung des Druckes als eine Injection des Systems aufzufassen habe, bei welcher die einzelnen Theile des- 
selben etwas ausgedehnt und Uebergänge von weiten zu engen Stellen vielfach ausgeglichen sind. Die Darstellung gelingt constant nach der folgenden Methode:

Einen möglichst frisch ausgeschnittenen Bulbus, mit Papier oder Leinwand umhüllt, setze man, mit der Hand die Aequatorialgegend umfassend, einem langsam ansteigenden kräftigen Drucke aus. Dabei wird die Hornhaut trübe; man lasse dann mit dem Drucke nach, bohre mit spitziger Nadel die Sclera durch, und umschneide von diesem Bohrloch aus mit scharfer Scheere die Hornhaut, und zwar etwas nach einwärts vom Scleralborde, damit dann beim Abheben der Hornhaut dieselbe nicht noch von anhaftenden Theilen losgezerrt werden brauche. Quetschungen durch stumpfe Instrumente müssen vermieden werden. Man breite die Hornhaut direct vom Bulbus aus möglichst platt auf ein objectglas, und träufle starke Eisenchloridlösung $(1+5)$ auf die Endothelfläche auf. So bleibe das Präparat 3-5 Minuten stehen, dann tauche man sie langsam einmal unter Wasser, breite sie schnell wieder aus, und tropfe ganz schwache Lösung gelben Blutlaugensalzes für 15 bis 25 Secunden auf. Sodann spüle man den anhaftenden grünblauen Farbstoff durch abermaliges Eintauchen in Wasser wenigstens theilweise ab. Kräftigere abspülende Bewegungen dürfen Vorsichts halber nicht vorgenommen werden. Man kann sich leicht überzeugen, dass das Resultat, auf welches es hier ankommt, auch dann eintritt, wenn das Eintauchen in Wasser ganz vermieden wird. Zwar bietet die Hornhaut jetzt noch kein kunstgerechtes mikroskopisches Präparat dar; weil aber die Manipulation des sofortigen Abziehens der hinteren Hornhautwand den grössten Theil des dargestellten, äusserst leicht verschieblichen Netzes verscbwinden macht, so muss man sich zunächst begnügen, die plattesten Stellen des Präparates mit mittelstarken Linsen zu betrachten, um nur erst einen Ueberblick zu gewinnen. Sodann kann man einen Theil in Alkohol legen, um platte Stücke ganzer Hornhänte zur Einbettung in Canadabalsam vorzubereiten, wobei es gut ist, dem Alkohol einige Tropfen Essigsäure zuzusetzen. Einen anderen Theil legt man für einige Tage in angesäuertes Glycerin, um dann erst für starke Linsen Präparate vorzubereiten, indem man mit Schonung eine möglichst dünne Schicht von der hinteren Hornhautwand abzieht. Nur bei einem Theil der so erhaltenen Präparate, die man auch in 
angesåuertes Glycerin einbetten, oder jetzt noch für den Canadabalsam präpariren kann, wird man dann die Röhrchen so gut erhalten finden, dass man die zahlreichen Details derselben mit starken Vergrösserungen studiren kann. Jedoch geht von der Charakteristik des Bildes durch das Abziehen stets viel verloren. Menschliche Hornhäute zeigen das System in ganz analoger Weise wie diejenigen der Schlachtthiere. Ausser den hier in Frage kommenden Röhrchen zeigen sich bei diesen Präparaten fast gar keine anderweitigen Färbungen (Fig. 2, abgezogenes Präparat).

Allgemeine Eigenschaften.

Man findet auf dem frisch bereiteten Präparate unter den umherschwimmenden Farbstoffschollen eine grosse Anzahl röhrchenartiger Gebilde, zum Theil von überraschend grossem Umfange; mitunter endigen dieselben mit einer granulirt erscheinenden kernartigen Masse; die kleinsten Formen haben oft trompetenartige Erweiterungen, und stellen dann immer Endstücke vor. Die Röbrchen sind zum Theil ganz blaugefärbt, zum Theil mit doppeltem Contour (vergl. auch Taf. VII. Fig. 6. 1. c.). Das sind isolirte Theile von dem System, das nun beschrieben werden soll (Fig. 1). Im frisehen Zustande sind sie ganz blass, verändern sich nicht merklich durch Essigsäure, sind tingirbar in Carmin, und werden oft in Zusammenhang mit Kernen oder Zellen angetroffen. Die Färbung tritt unter dem Druck des Deckgläschens oft im Laufe einiger Stunden aus; deshalb werden sie am Besten in Balsam eingebettet aufbewahrt.

Als ersten Satz muss ich hinstellen, dass an jeder Stelle der hinteren Hornhautwand ohne wesentliche Differenzen das System dieser Röhrchen dargestellt werden kann, wenn sich auch nicht jedes Präparat in so vollkommener Weise darbietet. Man begegnet wohl dicht am Rande häufig grösseren Dimensionen der Röhrchen, so dass man glauben könnte, hier Hauptstämmchen vor sich zu haben; doch überzeugt man sich gelegentlich, dass auch an centralen Stellen dergleichen angetroffen werden.

Was die Lage betrift, so ist das Bereich der Endothelzellen selbst und deren unmittelbare Basis als Verlaufsschicht zu bezeichnen.

Der Verlauf der Röhrchen ist entweder gestreckt, oder geschlängelt; oft sind rosenkranzartige Ausbuchtungen an einander 
gereiht, wobei Bilder zum Vorschein kommen, welche einer zusammenhängenden Kette von Kernen täuschend ähnlich sehen. Das Endstück ist oft gradlinig verlaufend und zeigt trompetenartige Formen. - Oft auch ist die Continuität der Röhrcben, soweit man sie nach der Färbung beurtheilen kann, mehrfach unterbrochen, wie wenn die Röhrehen sich aus lauter kleinen Bruchstücken zusammensetzten. Häufig sind sie so dicht neben einander gedrängt, dass das Ganze wie ein verwickelter Knäuel aussieht. Sehr oft sind ferner Ring- und Schlingenbildungen (Fig. 2).

Die Länge und Breite schwankt innerhalb weiter Grenzen; man hat den verständlichsten Maassstab in den Dimensionen der an ihnen liegenden Endothelzellen; die grösste Breite beträgt reichlich bis zu einem ganzen Durchmesser einer Endothelzelle; die grösste Länge eines ohne Communication zu verfolgenden Röhrchens etwa 8 bis 10 solcher Durchmesser. Jedoch lässt sich, wie wir seben werden, mit Sicherheit annehmen, dass die Möglichkeit von Communicationen im Bereiche jeder einzelnen Zelle vorhanden ist. -

Die Mündungen der Röhrchen und ihr Verhältniss zu den Endothelzellen.

Obgleich der Gesammteindruck die Vorstellung erweckt, dass der Verlauf dieses Systems nach allen Richtungen und scheinbar regellos die Zellenfelder kreuzt, so sind doch folgende bestimmte Beziehungen zwischen ihnen zu constatiren:

a. Beziehungen zu den Zwischenräumen der Zellen.

Erstens sehen wir, wie Fig. 3 a erläutert, um je eine Zelle bis zu 8 kleiner blaugefärbter Kreise. Dieselben liegen an den Knotenpunkten benachbarter Zellen. Sie sind identisch mit den Taf. VIII. Fig. 16. l. c. an dem isolirten Endothelhäutchen beschriebenen kleinen Kreisen. Dazwischen erubrigen längliche oder auch rundliche grössere Figuren (1. c. Taf. VII. Fig. 1 etc.), die früher obne eigene Deutung nach hergebrachter Bezeichnung ebenfalls Stomata genannt wurden, es aber nicht sind.

Fig. $3 \mathrm{~b}$ illustrirt, dass diese kleinen Kreise der Fig. $3 \mathrm{a}$ oft nur punktförmig angedeutet sind, dass sie aber auch oft viel grössere Dimensionen zeigen, und häufig von einer körnig tingirten Zellen- 
oder Kernmasse ausgefüllt erscheinen. Die grössten dieser Formen zeigen auch zuweilen deutlich eine charakteristische längliche Kernform mit gefärbter Membran.

Ferner sehen wir in etwas weiter vorgerücktem Stadium des Eindringens von Farbstoff, dass sich an diese rundlichen kleinen oder grösseren Kreise gefärbte Zipfel oder Röhrchen ansetzen (Fig. $3 \mathrm{c}$ ). Diese Röhrchen kommen von allen möglichen Richtungen ber. Die Figur erläutert aber, dass die eben erwähnten länglichen Gebilde der Zellenzwischenräume ebenfalls solche Röhrchen bedeuten, welche, indem sie den Zwischenraum der Zellen längsverlaufend passiren, an den kleinen runden Kreisen der Knotenpunkte münden. Neben ihnen kommen gleichbedeutende solche Röhrchen auch von allen anderen Richtungen her. Es ist auch etwas ganz Gewöhnliches, an Rissrändern des Endothelhäutchens Bilder zu sehen, wo das Röhrchen, den Längsverlauf fortsetzend, über den Rand hinausragt. Auch muss noch bemerkt werden, dass viele der Zipfel oder Röhrchenenden eine ausgesprochene Becherform besitzen.

Fig. $3 \mathrm{~d}$ zeigt wiederum, dass diese in den Zellenzwischenräumen vorhandenen Röhrchen auch 2 bis 3 Längsseiten einer Zelle als continuirliches Röhrchen passiren können, um dann erst an einem der kleinen Kreise zu münden. - Auch sieht man solche Röhrchen continuirlich mebrere Zellenfelder einschliessen, obne deutliche Abzwejgungen nach der Mitte der dadurch entstehenden grösseren Felder. Dies ist das Bild der früheren Fig. 5 (1. c. Taf. VII). Ich habe kein einziges Mal beobachtet, dass die länglichen oft auch rundlichen grösseren Gebilde der Zellenzwischenräume, welche zwischen den Knotenpunkten gelegen sind, also die früher beschriebenen sog. intercellulären Vacuolen, die Rolle von Ausmündungen spielen; vielmehr sind es längsverlaufende röhrchenartige Gebilde, welche sich nach Fig. 3d mannichfach eingeschaltet zeigen in ein noch reicher verzweigtes allgemeines Röhrchennetz. Die Ergebnisse der Resorption körnigen Farbstoffs und der Einstichsinjection steben mit dieser Darstellung in vollkommener Uebereinstimmung. Diese Methoden werden erst später besprochen. Mit Höllenstein habe ich diese Verhältnisse bisher nicht deutlich darstellen können. - Ueber den Oeffnungscharakter der Stomata an den Knotenpunkten der Zellen und die weitere Auffassung derselben kann ich mich erst weiterhin aussprechen. 
b. Beziebungen der Röhrchen zu den Kernmembranen der Endothelzellen.

Diese zeigen ebenfalls deutlichen Zusammenhang mit dem geschilderten System. Ich hatte schon früher (I. c. Seite 348) die Füllbarkeit der Kernmembranen angegeben, und auch erwähnt, dass ich durch Resorptionsversuche mit körnigem Farbstoff eine Bestätigung dieser Anschauung erlangt hätte. Auch kann ich hinzufügen, dass mir die Silberbehandlung öfters ganz analoge Resultate geliefert hat. - Bei der möglichen Tragweite dieser Auffassung der Kernmembran schien es mir jedoch angemessen, über jene Resorptionsversuche genauere Angaben zu machen.

Brugsch ${ }^{1}$ ) hat bei seinen Injectionen in die vordere Kammer des lebenden Kaninchens ein Eindringen körnigen Pigmentes in Zellen constatirt, und zwar nicht nur an der hinteren Hornhautwand, sondern auch auf und in der Iris. Er hielt es für möglich, dass sich die Körnchen direct in das zähweiche Protoplasma eingedrückt haben könnten. Calberla ${ }^{2}$ ), der ähnlich experimentirte, macht über diesen Punkt keine Angaben. - v. Recklinghausen, und nach dessen Vorgang Rajewsky und Foà, sowie auch Arnold, haben Resorptionsversuche mit chinesischer Tusche vielfach zur Untersuchung des Bindegewebes und der Lymphgefässe benutzt; aus Folgendem wird hervorgehen, dass diese Methode auch für die Beurtheilung von Zellen vortheilhaft verwerthet werden kann.

v. Recklinghausen ${ }^{3}$ ) hatte sich mit Erfolg über die Leydig'schen "pigmenthaltigen Bindegewebskörper“ durch Injection gefärbter öliger Massen dahin orientirt, dass diese Zellen wirklich offenen Zusammenhang mit Lymphbahnen zeigten; auch die Arnoldschen Figuren in diesem Archiv Bd. 62. Taf. III demonstriren von der Schwimmhaut des Frosches ein ähnliches Verhältniss, und zeigen namentlich auch die Anastomosen der Pigmentzellen mit benachbarten pigmentfreien Saftkanälchen. - Auch die Untersucher pathologischer Pigmente bis in die neueste Zeit [Virchow ${ }^{4}$ ), Gussen-

1) Brugsch, Ueber die Resorption börnigen Farbstoffs aus der vorderen Augenkammer. Arch. f. Ophth. Bd. 23. III. dazu Tafel VII.

2) Calberla, Pflüger's Archiv Bd. IX. S. 468.

3) v. Recklinghausen, Die Lymphgefässe etc. S. 74.

4) Virchow, Die pathologischen Pigmente. Dieses Archiv Bd. I. S. 379. 
bauer ${ }^{1}$ ), Kolaczeck ${ }^{2}$ )] sind darin einig, dass sich Pigmentzellen gar nicht von anderen nicht pigmentirten Zellen gleichen Charakters, z. B. des endothelialen, unterscheiden. Es wird daher von Interesse sein, wenn der Nachweis geliefert wird, dass man nichtpigmentirte Zellen kunstlich in Pigmentzellen umwandeln kann, welche den gleichen Charakter wie natürliche Pigmentzellen an sich tragen, und das Interesse wird sich erhöhen, wenn man nachweisen kann, dass diese künstliche Bildung von Pigmentzellen immer in der gleichen Weise und auf bestimmten nachweisbaren Wegen erfolgt. Ich brauche nur anzudeuten, dass damit der Begriff eines anastomosirenden Zellennetzes, der ja so mannichfache Wandlungen erlebt hat, eine bestimmtere Form annebmen kann.

Betreffs der Epithelien und Endothelien sind, auch bei Versuchen an lebenden Thieren, Färbungen im Bereiche derselben, namentlich an Kernen, z. B. von Arnold ${ }^{3}$ ) beobachtet worden; derselbe sagt darüber, dass man solche Bilder wohl auf Imbibition zurückführen müsse; jedoch schien es mir, als ob ihn diese Erklärung nicht recht befriedigte. Auch fand Ulrich ${ }^{4}$ ) an den Kernen der Linsenfasern einen blauen Saum, der dort ebenfalls als ein intra vitam von Blutlaugensalz passirter Flüssigkeitsweg aufgefasst werden muss. - Es dürfte sich noch manche derartige Beobachtung auffinden lassen.

In diesem Capitel wird die Umwandlung von Endothelzellen, in einem späteren die von "Saftkanälchen“ in Pigmentzellen beschrieben werden.

Künstliche Pigmentzellen kann man sowohl an ausgeschnittenen Hornbäuten herstellen, indem man dieselben, mit der Endothelseite nach oben, in eine Anreibung chinesischer Tusche direct hineinlegt, und einige Stunden liegen lässt, oder man kann auch die Anreibung der Tusche in die vordere Kammer injiciren, nachdem man etwas Kammerwasser entzogen hat. Den mit möglichst vielen anhängen-

1) Gussenbauer, Ueber die Pigmentbildang in melanotischen Sarkomen etc. Dieses Archiv Bd. 63. S. 322.

2) Kolaczeck, Zur Lehre von der Melanose der Geschwülste. Deutsche Zeitschr. f. Chirurg. Bd. XII. S. 67.

3) Jullus Arnold, Ueber die Kittsubstanz der Endothelien. Dieses Archiv Bd. 66. Siehe Seite 90 unten.

4) Ulrich, Ueber die Ernährung des Auges. Arch. f. Ophth. Bd, 26. III. S. 42. 
den Fleischtheilen bedeckten Bulbus setze man dann mit der Hornhaut nach unten in einen stetig sich zuspitzenden Becher (Eierbecher) ein, so dass die Aequatorialgegend des Bulbus den Becher dicht abschliesst, ohne dass die Hornhaut den Boden berührt. Oft constatirt man ein sichereres Resultat, wenn man vorher mit scharfem Rasirmesser durch Abtragen einer dünnen Schicht einen vorderen Epithelverlust an der Hornhaut verursacht hat. Wir werden später (Theil II) hierfür eine Deutung finden. Der Bulbus bleibe bis höchstens 24 Stunden stehen. Nimmt man ihn dann heraus, so ist der nach unten im Becher befindliche Theil nass, und aucb die äusseren Theile wurden durch die anhängenden Fleischtheile vor Eintrocknung geschützt. Jetzt schneidet man durch die frühere Bohröffnung in der Sclera die Hornhaut aus, spült sie durch mehrmaliges Untertauchen in Wasser ab, und bringt sie zur Beobachtung. Hat man sich an der Endothelseite vom Gelingen überzeugt, so schreite man auch zur Herstellung eines für starke Vergrösserungen zugänglichen aufzubewahrenden Präparates, indem man einige Tropfen starker Eisenchloridlösung auf die Endothelschicht auftropft, oder die Hornhaut ganz hineinlegt, und dann bis zu einer Stunde stehen lässt. Danach zieht man entweder bald, oder nach tagelanger Aufbewahrung in Glycerin die Hinterwand der Hornbaut in möglichst dünner Schicht ab. Das grösste Hinderniss liegt stets in den pigmentirten Randtheilen, weshalb man diese erst sorgfältig abschneiden muss.

Das Eisenchlorid hat jetzt die Zellenlage soweit fixirt, dass man zur nochmaligen besseren Reinigung ein sanftes Abpinseln unter Wasser riskiren kann. Bei der Untersuchung wird man sogleich unterscheiden, wo der Farbstoff präformirte Bilder markirt, oder wo er etwa nur noch auflagert. Wir finden da die Endothelzellen in allen möglichen Stadien der Pigmentirung, meistens nur an vereinzelten Theilen der ganzen Fläche. Hier kommt es vor Allem darauf an, dass wir unzweifelhafte Bilder gefüllter Kernmembranen vor uns sehen, wie es Fig. 4 illustrirt. An vielen Zellen sehen wir dabei deutlich den Weg markirt, auf dem der Farbstoff zur Kernmembran gelangt; es sind dies die positiven Bilder jener Kernfortsätze, welche ich durch Berlinerblau als negative dargestellt hatte (1. c. Fig. 17). Dann finden wir wieder alle Uebergänge bis zur vollständig dicht gefüllten Zelle mit weissem Kern. Machen wir zwei erfolgreiche Parallelversuche, z. B. mit 
einer Ochsen- und einer Hammelhornhaut, so werden wir auch bei dieser Methode noch den mehr bohnenförmigen Kern des Hammels von dem ovalen des Ochsen unterscheiden. Von einer blossen Auflagerung des Farbstoffs wird kaum Jemand sprechen, der ein gelungenes Präparat dieser Art gesehen hat, weil uberall die Grenzen, sowohl des Kerns wie der ganzen Zelle und jedes etwa vorhandenen Ausläufers scharf markirt sind. Hie und da wird auch ein weiss gebliebener Fortsatz des Kerns beobachtet, wie dies auch an den natürlichen Pigmentzellen des Hornhautrandes der Fall ist. - Die zu beobachtenden Uebergangstadien der Färbung lassen sich aber ganz genau zergliedern und auf ein verzweigtes präformirtes Kanälchensystem zurückführen.

Fig. 4 zeigt genau gezeichnete Formen der Kernfortsätze innerhalb des Zellenleibes an schwarzen Tuschepräparaten. - Fig. 5 erläutert an negativen Berlinerblaupräparaten noch detaillirtere, aber scharf gezeichnete Formen dieser Art, die wir in ähnlicher Weise schon von der früheren Fig. 17. Taf. VIII. l, c. kennen.

Hiernach kann man in der That von einer Canalisation der Zellen sprechen, und es kann sich eine darin befindliche Masse erklärlicherweise sehr verschiedenartige Wege des Fortschreitens wählen. So werden wir uns über Figuren wie $6 \mathrm{a}$, welche wir im Verfolge der Lymphröhrchen innerhalb von Zellenfeldern vielfach antreffen, nicht mehr wundern können, und werden auch begreifen, dass von jeder beliebigen Stelle dieses Kanälchennetzes aus die Färbung oder Füllung der Zelle beginnen kann, so dass z. B. neben dem Kern innerhalb des Zellenleibes umschriebene Färbungen nach dem häufig beobachteten Schema der Fig. $6 \mathrm{~b}$ vorhanden sein kön̨̧en, die man mit Kernen nicht verwechseln darf.

Trotzdem nun diese auf künstlichem Wege erzielten Resultate der Füllung von Zellen, wie ich glaube, eine erhebliche Beweiskraft haben, so glaube ich doch mit noch mehr Nachdruck auf ein natürliches vitales Beispiel dieser Art aufmerksam machen zu können, dessen Analogie mir in letzter Zeit regelmässig aufgefallen ist. Dasselbe betrifft

Die Pigmentzellen des Hornhautrandes.

Wenn man an einer Anzahl frischer Bulbi die Hornhäute bis zum äussersten Rande ausschneidet, und mit der Endothelseite 
nach oben auf ein Objectglas breitet, so trifft man regelmässig an Stellen des Randes Gruppirungen des braunkörnigen Pigmentes, wie es Fig. 7 erläutert. Man sieht da erstens scheinbar freie einzelne braune Körnchen, an einer anderen Stelle aber deutlich einer geraden Richtung folgend. Anderswo schliesst sich wieder ań den mit Körnchen erfüllten röhrchenförmigen Fortsatz eine ganz oder theilweise angefülte deutliche Form einer Kernmembran an; wieder an anderer Stelle ist um den weissen Kern mit oder ohne weissen Fortsatz ein Häufchen Körner gelagert, welche, wie ein vorurtheilsloser Blick zu lehren scheint, zweifellos den zu dem weissen Kern gehörigen Zellenleib mehr oder weniger vollständig anfüllt. Wir constatiren da bei häufiger wiederholten Untersuchungen in immer gleicher Weise wiederum alle Uebergänge der Füllung. - Ist dies nicht ein Beispiel für den natürlichen Vorgang einer intracellularen Leitung körnigen Farbstoffs? Und dürfen wir nicht annehmen, dass dies einen der natürlichen Bildungsmodi von Pigmentzellen bedeutet? - deshalb glaube ich auch fragen zu müssen, wo dieses körnige Pigment herstammt, und habe hier, abgesehen von anderen Möglichkeiten, diejenige im Auge, dass bier der Farbstoff, dem allgemeinen Flüssigkeitsstrome folgend, von untergegangenen Pigmentepithelien oder destruirten rothen Blutkörperchen stammend, aus der vorderen Kammer in jene Zellen resorbirt sein könne, wobei zugleich die Zone der Pigmentzellen andeutet, in welchem Bereiche wir vielleicht unter normalen Verhältnissen den Abfluss des Kammerwassers nach aussen anzunehmen haben. Die Breite dieser Zone der Pigmentzellen ist ausserordentlich schwankend. - $\mathrm{Ob}$ wohl ich in dieser Abhandlung pathologische Zustände noch nicht zu berühren beabsichtige, so muss ich doch einer Mittheilung gedenken, der von $\mathrm{Knies}^{1}$ ) über Iritis serosa, in welcher gewisse Anschauungen auf Grund der mikroskopischen Untersuchung jener Beschläge der hinteren Hornhautwand zum Ausdruck gelangt sind, welche die hier vertretene Auffassung zu unterstützen geeignet sind. Dort wird die Meinung ausgesprochen, dass diese Beschläge, welche aus pigmenthaltigen Detritusmassen bestehen, vorzugsweise zu den Zellenzwischenräumen Beziehungen erkennen lassen, und ganz den Eindruck machen, als ob sie dem allgemeinen Flïssigkeitsstrome folgten. - Ich kann für die ausgesprochene Vermuthung folgendes

1) Knies, Archiv v. Knapp und Hirschberg. Bd. IX. 
normale anatomische Bild geltend machen. - In den äussersten Randpartien der frisch ausgeschnittenen Hornhäute findet man vollkommen das gleiche braunkörnige Pigment, das wir vorhin kennen gelernt haben, nicht selten auf grosse Strecken in den Zwischenräumen der Endothelzellen an, und bei einer Spur tieferer Einstellung beginnen wieder einzelne Anhäufungen dieser Kügelchen in Formen, welche mit Sicherheit auf fortschreitende Füllung von Zellen schliessen lassen (Fig. 8). Man kann die Lage derselben zuweilen in die Endothelzellen selbst, zuweilen in die Basis der Zwischenräume, resp. in die daselbst befindlichen Saftkanälchen verlegen, obgleich natürlich das Gros der Pigmentzellen stets in den Hornhautschichten selbst liegt, was unserer Annahme vollkommen entspricht. Ein weiterer sicherer Beleg wird erst darin zu finden sein, dass ich sogleich noch die Lage dieser Saftkanälchen und ihre künstliche Umwandlung in Pigmentzellen beschreiben, und im II. Theile die Verhältnisse der Permeabilität der Descemetschen Haut genauer erläutern werde. Hier flihre ich nur noch an, dass die Flächenbilder nicht darauf deuten, dass man bei Querschnitten zusammenhängende Körnchenreihen, welche die Membran senkrecht durchsetzen, vorfinden würde, was auch wegen der Verschieblichkeit der Körnchen schon unmöglich sein dürfte; vielmehr sammeln sich die Körnchen, einzeln tiefer rückend, immer flächenhaft zu Häufchen an, entsprechend der platten Ausbreitung der Structurelemente.

Kehren wir jetzt zu dem Zusammenhang der Kernmembranen mit den Lymphröhrchen zurück. - Figg. 9a, b, c schildern dabei zu beobachtende Bilder, deren Mannichfaltigkeit sich durch Zeichnungen nicht erschöpfen lässt; denn wohin wir auch blicken, - überall scheinen Beziehungen zwischen Kernen und Lymphröhrchen obzuwalten. Fig. 9 a wird nach der bisherigen Darstellung verständlich sein; dagegen überrascht $b$ und $c$ durch die eigenthümliche Anordnung der Kerne, deren Membranen sich zu fortlaufenden Liniensystemen gruppiren, und die Wand jener Röhrchen mit zu bilden scheinen. Dieses letztere Verhältniss ist durchaus nichts Ungewöhnliches, und anch an den isolirten Gebilden finden wir den Zusammenhang ausgeprägt. Auch muss ich darauf aufmerksam machen, dass an jenen sog. elastischen Balken des Iriswinkels, in welche sich die Membrana Descemeti auflöst, ganz 
ähnliche Beziehungen ersichtlich sind. - Von weiteren Erklärungsversuchen solcher Bilder sehe ich einstweilen $a b$, und spreche nur die sebr nahe liegende Vermuthung aus, dass das Verhalten der Kerne, resp. der ganzen Zellen, auf die Gruppirung des Röhrchensystems offenbar einen Einfluss zu haben scheint. - Eine hierher gehörige Beobachtung ist noch mitzutheilen. Früher wurde erwähnt, dass die Lymphröhrchen ein ausserordentlich verschiebliches System darstellten. An den isolirten und nicht isolirten Röhrchen erkannten wir oft eine Zusammensetzung aus Bruchstücken, zuweilen in der Form an einander gereihter Kerne. Wenn man nun z. B. an einem menschlichen Leichenauge die Darstellung der Röhrchen vornimm', und sich vom Gelingen in der Form des beschriebenen Bildes überzeugt hat, so ist man überrascht, dass man an der sodann abgezogenen hinteren Hornhautschicht von den Röhrchen gar Nichts mebr, oder nur lauter Bruchstücke vorfindet. Achtet man genauer auf die eingetretene Aenderung, so überzeugt man sich zuweilen, dass jetzt Färbungen im Gebiete der Zellen und ihrer Zwischenräume in Form kleiner Bruchstücke vorhanden sind, während man vorher nur fortlaufende röhrchenartige Bilder gesehen hatte. Die perlschnurartige Form, welche in ausgeprägtesten Exemplaren wie eine Reihe an einander gereihter Kerne aussieht, scheint eine lllustration zu dieser Zusammensetzung aus Brucbstücken vorzustellen. In der That könnte man kaum glauben, dass ein wirklich hohles Röhrensystem von theilweise so riesigen Dimensionen, den zahlreichen darauf gerichteten Untersuchungen und Injectionen entgangen sein könnte. Ist dasselbe aber von Gruppirungen der Zellen oder Kerne mit abhängig, so sind auch die in diesen nachgewiesenen Wege bei dem Röhrensystem mit in Betracht zu ziehen, und es kann so ein System sich formiren, welches zwar als Hoblsystem aufzufassen, aber doch gleichzeitig als von Zellmaterial erfüllt anzusehen ist. - Sobald diese Vorstellungen auch auf das System der Saftkanälchen ausgedehnt werden können, dürften sich vielleicht die divergirenden Meinungen darüber auf die angedeutete Weise vereinigen lassen.

Im Ganzen stellt sich demnach das Verhältniss der Endothelzellen folgendermaassen:

Die Zellen unterhalten erstens direct durch Kernfortsätze zu den kleinen Stomata Beziehungen, und sind im Stande, von diesen 
aus sich aus der vorderen Kammer mit Flüssigkeiten wie körperlichen Substanzen anzufüllen (vergl. hier auch Taf. ViII. Fig. 7. I. c.).

Zweitens hängen sie auch unter einander durch Anastomosen zusammen und können aufgenommene Stoffe in ihrem Bereiche fortleiten.

Drittens hängen sie mit dem Röhrchensystem zusammen, und können in dieses Stoffe abführen, oder aus ihnen aufnehmen (vergl. auch die später folgenden Resorptions- und Injections-Resultate).

Viertens können, wie es scheint, durch Gestalt- oder Richtungsveränderungen der Kerne oder Zellen die beschriebenen Leitungsrichtungen mannichfach variirt werden.

Der Schwerpunkt dieser Resultate muss meines Erachtens zunächst in dem Nachweis der Wege gesucht werden, auf welchen corpusculäre Gebilde in Zellen eindringen und in deren Bereich sich weiter bewegen oder bewegt werden können - eine wichtige Frage der allgemeinen Pathologie.

Das Verhältniss der Saftkanälchen zu den Endothelzellen und dem System der Lymphröhrchen.

Wir wollen dasselbe ebenfalls wieder an positiven wie an negativen Bildern verfolgen, deren vergleichende Betrachtungen die sicherste Garantie gegen Irrthümer zu bieten scheinen. Die beiden in der Ueberschrift enthaltenen Beziehungen lassen sich nicht gut gesondert behandeln.

Um die hier in Betracht kommenden negativen Bilder herzustellen, empfehle ich am meisten den Eingangs beschriebenen Versuch der Darstellung der Lymphröhrchen jetzt an einem Augapfel vorzunehmen, welcher schon 15 bis 24 Śtunder post mortem alt ist. Es zeigen sich da mitunter bei der Untersuchung vereinzelte Endotheldefecte, und solche Stellen sind es gerade, welche zuweilen die hierfür brauchbare Zeichnung enthalten. Fig. 10 erläutert z. B. eine solche genau copirte Stelle. Die an der Basis der Endothelzellen vorbandenen Saftkanälchen liegen daselbst frei zu Tage, und ihre Ausläufer setzen sich ringsum in die Endothelschicht hinein fort. Bei genauer Betrachtung ergiebt sich, dass diese Ausläufer alle jene von dem Lymphröhrchensystem uns bekannten Formen und Beziehungen zeigen. Wir sehen an solchen Präparaten mit Deutlichkeit feine weisse Fäden an Kernmembranen der Endothel- 
zellen herantreten; auch kreuzen die Fortsätze sehr vielfach die Zellen und gehen dicht an deren Kernen vorbei. Ferner richtet sich stellenweise ihr Verlauf auch wieder nach einigen Zellenzwischenräumen. Sodann erkennen wir, dass meistens die erweiterten Stellen dieses weissen Systems gerade an den Knotenpunkten benachbarter Endothelzellen liegen. $\mathrm{Zu}$ betonen wäre also, dass wir hier die beschriebenen Lymphröhrchen, wie es scheint, direct von Ausstrahlungen der Saftkanälchen ableiten können, deren Lage wir in die Gegend der Knotenpunkte der Endolhelzellen verlegten. - Nachdem wir diese Präparate kennen gelernt haben, fallen uns nun auch an manchen Stellen solche weisse verzweigte Liniensysteme auf, welche durch die intacte Endothelzellenlage hindurchschimmern, auch wo wir dieselben nicht bis zu einem Endotheldefect verfolgen können. Trotzdem werden wir jetzt mit Sicherheit auch diese Liniensysteme in der angefübrten Weise zu deuten wagen, zumal wir wiederum die charakteristischen Beziehungen erkennen. - Man erhält hierbei zuweilen ausserordentlich deutliche Bilder. -

So gross die Klarheit dieser vegativen Bilder auch ist, so erreichen sie bei Weitem nicht die Beweiskraft der durch Tusche und auch durch Berlinerblau hergestellten positiven Bilder. Denn Alles, was innerbalb der weiss bleibenden Theile etwa zu beobachten wäre, tritt bei ihnen nicht in deutlicher Form zu Tage. Wohl erkennen wir hie und da, namentlich nach Zusatz von Essigsäure, zellige Elemente in den weissen Stellen, werden auch oft mit einiger Sicherheit Kernformen in ihnen sehen, welche mit denen der Fndothelzellenkerne gleichen Charakters sind; aber wir wagen es nicht, nur auf solche Bilder gestutzt, feste Meinungen auszusprechen. Deshalb versuchte ich, diese oberflächlich gelegenen Saftkanälchen, die, wie ich in Rücksicht auf ihre Lage an den Knotenpunkten hoffte, ohne Lädirung der Theile darstellbar sein müssten, für die Beurtheilung der Saftkanälchen zu verwerthen.

Für gewöhnlich erhält man, wie bekannt, bei Resorptionsversuchen mit chinesischer Tusche zuerst, oft schon nach wenigen Minuten, intensive Schwärzung der Zellenzwischenräume, während der mittlere Theil der Zellenfelder frei bleibt. Eine Zergliederung dieser Färbung der Zellenzwischenräume, d. h. die Erkenntniss der Wege, wie sie $\mathrm{zu}$ Stande $\mathrm{kam}$, ist an diesen Bildern nicht zu erreichen. Wenn man aber eine grössere Zahl solcher Versuche macht, und 
wieder eînen nicht zu starken Druck der Augäpfel zu Hülfe nimmt, so erhält man zuweilen Bilder, welche die eben berührte Deutungsfähigkeit ohne Zweifel besitzen. Auch ohne Druck werden sie zuweilen erzielt. Man verwendet am besten bald mehrere Hornhäute, und legt dieselben, mit der Endothelseite nach oben, in die Tuscheanreibung hinein. Es ist gut, wenn man die Scbälchen recht oft schïttelt, um eine starke Auflagerung des Farbstoffs zu verbüten; auch braucht man nur schwache Anreibungen in gewöhnlichem Wasser oder schwacher, höchstens 0,75 procentiger Kochsalzlösung zu verwenden. Man muss schon nach 15 Minuten zu untersuchen anfangen, und dieselbe nach eben so langen $Z$ wischenpausen wiederholen. Dabei wird man recht oft, meistens schon nach einer halben Stunde oder früher, Bilder sehen, wie sie in Fig. 11 getreu dargestellt sind. Dieselben erstrecken sich mit grosser Regelmässigkeit oft über die ganze Fläche der Hornhaut. Es ist natürlich am Sichersten, dieselben an den ganzen Hornhäuten sogleich zu studiren; aber es gelingt doch auch, nachdem in der früher angegebenen Weise die Zellenlage durch Eisenchlorid fixirt wurde, wieder eine dünne Schicht abzuziehen, und diese mit ziemlich guter und regelmässiger Erhaltung der Zeichnung, die schon eine vorsichtige Reinigung vertragen konnte, für starke Vergrösserungen zugänglich zu machen. Die Untersuchung lehrt nun; dass man hier die an den Knotenpunkten der Endothelzellen lauernden Saftkanälehen, wie wir sie vorhin auch an den negativen Bildern kennen gelernt haben, mit Tuschekörnchen gefüllt, vor sich hat. Die charakteristische Form derselben ist nicht zu verkennen. Die Fortsätze derselben zeigen sich zum Theil schon auf weitere Strecken gefüllt, zum Theil noch leer. Hauptsächlich aber muss ich betonen, dass man in ihnen wieder an vielen Stellen mit Deutlichkeit Kerne mit gefüllter Membran und von ihr ausgehenden Fortsätzen erkennt. Die Fortsätze verzweigen und verbinden sich in der uns bekannten Weise unter einander, und mit den Kernen der Endothelzellen, an denen wir hie und da auch schon gefüllte Membranen antreffen. - Ein Theil der Fortsätze ist kurz und geht direct an nahe gelegene Knotenpunkte; ein anderer Theil setzt sich weiter fort, und mündet erst an entfernteren Stomata, geht auch mannichfache Anastomosen ein, die wir nicht immer bis zu Mündungen verfolgen können. - Im Ganzen erkennen wir deutlich die Ana- 
logie der hier positiv dargestellten Verzweigungen mit jenen der Berlinerblaupräparate, und haben hier wieder den Beweis für die Oeffnungsnatur jener Stomata, welche an den Knotenpunkten von Endothelzellen gelegen sind.

Nachdem wir dieses festgestellt haben, bieten uns die Berlinerblaupräparate, wie sie sich gleich nach der Darstellung an frischen wie älteren Hornhäuten in mebr oder weniger gleichmässiger Weise an platten Stellen der ganz gebliebenen Hornbäute präsentiren, das am meisten lehrreiche Bild dar. Ihre Wichtigkeit liegt darin, dass wir an ihnen mit scheinbar untrügerischer Sicherheit die Saftkanälchen in ebenfalls positiver Darstellung als die Knoten- oder Ausgangspunkte des gesammten Lymphröhrchensysiems erkennen.

Es ragen da aus der Gegend der Knotenpunkte von Endothelzellen mit stachligen Kernfortsätzen versehene Zellen heraus, die auch ganz austreten können, wie uns zahlreiche weisse Flecke oder Löcher beweisen, die an den entsprechenden Stellen der Nachbarschaft angetroffen werden, nachdem wir vorher an den ganzen Hornhäuten daselbst ebenfalls die stachligen Figuren constatirt, dann aber die Hinterwand der Hornbaut abgezogen baben (Fig. 12 a). Fig. $12 \mathrm{~b}$ erläutert das Aussehen solcher isolirter Gebilde mit anhängenden Röhrchenstücken; dieselben sehen im isolirten Zustande nicht so charakteristisch aus, weil die meisten der stachligen Fortsätze abgefallen sind. Diese rundlichen Gebilde liegen also, entsprechend den fruher beschriebenen positiven wie negativen Bildern, an Knotenpunkten der Endothelien, können sich aber auch weit in das Gebiet der Zellenfelder binein erstrecken. Von ihnen sieht man nach allen Richtungen die Lymphröhrchen ausstrahlen, wie es Fig. 13 darstellt. Hierbei ist noch bemerkenswerth, dass die Zellenzwischenräume, bei der Vorbereitung der Präparate für den Canadabalsam, das Terpentinöl in sich aufnehmen können. Man sieht dann an solchen Stellen, was ohne Markirung der Zellengrenzen zuweilen zweifelhaft erscheinen kann, dass dieses mächtige Röhrchensystem wiederum im Niveau der Endothelzellen sich befindet.

Entweder sind da die ganzen stachligen Figuren blau gefärbt, und machen den Eindruck einer mit Stacheln besetzten Kugel (Fig. 12 a abgezogenes Präparat), oder es sind an den betreffenden Stellen deutliche Kernfiguren sichtbar. Jedoch finden wir an den stachligen Figuren oft Formen, wo wir innerhalb des ganzen, als 
vollständige Zelle aufzufassenden Gebildes den deutlichen Kern sehen. Sodann trifft man weisse Stellen, welche nicht so deutliche Kernform haben, und von einem gefärbten, zuweilen doppelt contourirten Rande umgeben sind. Die Röhrchen gehen in allen Fällen unmittelbar in die Färbung, welche die weisse Mitte umgiebt über, und oft ist dieser gefärbte Rand mit Sicherheit als Kernmembran aufzufassen. Zuweilen sieht man die Röhrchen sich um den Kern herum- oder abwickeln. Die Figuren der isolirten „Kittsubstanz" von Arnold (dieses Archiv Bd. LXIV. Taf. IX. Fig. 2) und meine frühere Zeichnung (l. c. Fig. 16) zeigen übereinstimmend an Knotenpunkten der Verzweigung Kernformen in dieselbe eingeschaltet, und ich habe mich jetzt überzeugen können, dass diese Figuren als Kernmembranen der an Knotenpunkten befindlichen Saftkanälchen aufzufassen sind. Die in ihnen oft sichtbare und früher erwähnte gekörnte Masse ist darauf zurülckzuführen. - Endlich aber trifft man auch Stellen, an deren Rande die zulaufenden Röhrchen scharf abgeschnitten endigen, wie in Fig. 12 c, da ist dann Kern oder Zelle mit gefärbtem Rande ausgetreten. Das letztere Bild ist bei Weitem das seltenste.

Diese zuletzt beschriebenen Arten sind die Anfangs erwähnten grösseren, zuweilen ebenfalls stomaähnlichen Gebilde, welche bei der Frage nach den "grossen Stomata " berührt wurden. Dieselben erscheinen oft in regelmässiger Weise von Endothelzellen umstellt. Ihre Deutung als Kerne oder Zellen, welehe den "Saftkanälchen“ vollständig entsprechen, kann nach meiner Meinung nicht zweifelhaft sein.

Halten wir hier einen kurzen Ueberblick! - Wir haben ein System beschrieben, dessen Oeffnungsnatur durch die Füllbarkeit mit körnigen Substanzen und durch den Nachweis der Mündungen bewiesen ist. Mit der geschilderten Auffassung der Lymphröhrchen ist jedoch nothwendig die Vorstellung verknüpft, dass sie, entsprechend ihrer Natur als Zellfortsätze, obgleich sie bohle Leitungswege enthalten, doch auch von Zellmaterial erfüllt sind. Dieses Zellmaterial erstreckt sich bis an die Ausmündungen, die wir entweder als Kernfortsätze von Endothelzellen oder als solche von „Saftkanälchen" aufzufassen haben. Diese Fortsätze können ganz 
kurz sein, indem sie an die der sie aussendenden Zelle zunächst gelegenen Stomata herantreten, oder sie können einen längeren, oft sehr langen, röhrchenartigen Verlauf hinter sich baben, und an entfernten Stomata endigen. Diese kurzen oder langen Röhrchen zeigen wieder überall Abhängigkeit von den an ihrem Wege liegenden Zellen oder Kernen. Es können aber an der Stelle der Stomata auch direct die Kerne selbst vorhanden sein, denen wir nach den uns bekannt gewordenen Einrichtungen und Verbindungen die gleiche Function der Aufnahme und Fortleitung von Stoffen zutrauen können. Der Ton ist darauf zu legen, dass, obgleich eine Ausfüllung mit Zellen- oder Kernmasse constatirt werden kann, dennoch in dem angeführten Sinne der wahre Oeffnungscharakter, d. h. die Fähigkeit der Aufnahme und Fortleitung auch corpusculärer Gebilde nicht bezweifelt werden darf.

Somit ist auch vielleicht der Einwand widerlegbar, welchen v. Recklinghausen dem Virchow'schen anastomosirenden Zellennetze gegenüber geltend gemacht bat, dass man sich nehmlich dann zwei in einander gesteckte Systeme vorzustellen habe, von denen das eine hohl das andere solide sei. In der That darf man, wie es scheint, von einer Art Hohlzellensystem reden.

Wir haben gesehen, dass sowohl Röhrchen wie auch die Gebilde an ihren Knotenpunkten, die Zellen, sich isoliren lassen, weshalb ich also das ganze geschilderte System, resp. alle Theile desselben als isolirbar bezeichnen muss. Der Ausdruck „Lymphröhrchen" schien der geeignetste zu sein, weil darin der Begriff der ejgenen Wandung zum sicheren Ausdruck gelangt. Will man für das ganze System einen besonderen Namen gebrauchen, so müsste nach meiner Meinung der Begriff anastomosirender Zellenkerne darin vertreten sein.

Was die Mündungen in die kleinen Stomata der Endotheloberfläche betrifft, so steht dies in Einklang mit zahlreichen Beobachtungen von Oedmannson, Arnold, Thoma, Klein und Burdon-Sanderson, Lavdowsky, obgleich die Deutungen derselben mannichfach variiren. Von Klein und Burdon-Sanderson muss ich die „Fortsätze der Saftkanälchenzellen“ zwischen die Endothelzellen, von Lavdowsky die Oeffnungsnatur der kleinen Stomata acceptiren. - Die hohe Bedeutung dieser Verhältnisse zu schildern, kann in dieser Arbeit nicbt meine Aufgabe sein. 
Im Wesentlichen musste ich an der Membrana Descemeti den geschilderten Arten der Stomata einen einheitlichen gleichartigen Charakter zuerkennen, weun sich dieselben auch an Grösse und Inhalt verschiedenartig darstellen. Ich muss mich darauf beschränken zu sagen, dass ich mich an der Membrana Descemeti bisher von einem System von Gefässen, welches sich als etwas von den anastomosirenden Zellen Abgesondertes oder Unabhängiges auffassen liesse, nicht überzeugen konnte, womit auch der Begriff einer besonderen Art von Stomata für die genannte Stelle wegfällt. - Eine eingehendere Beurtheilung der sebr umfangreichen Geschichte dieses Capitels wird vielleicht bei einer späteren Gelegenheit erfolgen können.

\section{II.}

Der Zusammenhang des Lymphröhrchensystems der Membrana Descemeti mit der. Hornbaut.

Wir haben jetzt im Bereiche der Endothelschicht Wege für flüssige wie körperliche Stoffe kennen gelernt. - Zunächst würde daraus hervorgehen, dass ein continuirlicher Endothelbelag Strömungen aus dem von inm bekleideten Raume oder in denselben hinein zulässt. Sobald nun eine ununterbrochene Endothelbekleidung für die ganze Wand der vorderen Kammer sammt den mit ihr communicirenden serösen Räumen des Iriswinkels festgestellt ist, so haben wir, wo immer eine Strömung oder ein Austritt von Stoffen stattfioden möge, zunächst diese Endothelpassage in Betracht zu ziehen.

An dieser Continuität des Endothelbelages kann aber, wie ich glaube, kaum gezweifelt werden.

Die Zeichnung Waldeyer's ${ }^{1}$ ) ist in dieser Beziehung die positivste. - Aber auch Iwan off und Rollett ${ }^{2}$ ), welche mehrmals die Schwierigkeiten betonen, die sich der sicheren Constatirung des continuirlichen Endothelbelages entgegenstellen, und demgemäss mit sehr vorsichtiger Kritik zu Werke gegangen sind, haben nicht nur am Menschen und den Såugethieren, sondern auch bei Vögeln mit

1) Gräfe-Sämisch, Handbuch I. S. 226 .

2) Alex. Iwa noff und Alex. Rollett, Archiv f. Ophth. Bd. 15. Bemerkungen zur Anatomie der Irisanheftung und des Annulus ciliaris.

Archiv f. pathol, Anat. Bd. LXXXVII. Hft. 1. 
voller Sicherheit constatiren können, dass von der hinteren Hornhautwand zur vorderen Irisfläche in durchaus continuirlicher Lage Endothelzellen nachweisbar sind; es sind nach ihnen, am deutlichsten bei Vögeln, an der hinteren Hornbautwand scharf polygonale, an der vorderen Irisfläche kleinere runde, und zwischen diesen beiden eine dritte Art noch kleinerer Zellen; aber nirgend sei eine Unterbrechung des Zellbelages vorhanden. Nachdem ferner Rollett und I wan off ${ }^{1}$ ) die Irisfortsätze mit einem gezähnten Rande an die Membrana Descemeti sich inserirend dargestellt hatten, wurde später von Koenigstein ${ }^{2}$ ) (nach dessen Angabe zuerst von Prof. Exner nach Präparaten eines seiner Schüler) und von Angelucci ${ }^{3}$ ) beobachtet, dass die genannte Membran von Irisfortsätzen durchbohrt würde. - Heisrath ${ }^{4}$ ), der ebenfalls diese schwierige Gegend sehr detaillirt beschreibt, spricht wieder nur von dem Hinanreichen der Irisfortsetzungen bis an die Descemet'sche Haut. Directe Angaben über das Verhalten des Endothels sind dort nicht gemacht; jedoch wird mehrfach gesagt, dass Irisbalken, welche mit der Membrana Descemeti zusammenstossen, von ihr eingescheidet werden. Koenigstein studirte namentlich auch Altersunterschiede dieser Verbältnisse, und traf an jugendlichen Individuen auf Präparate, wo die Membrana Descemeti noch nicht über die Irisfortsätze übergewachsen war; aber Angaben über das Verhalten des Endotheluberzuges an diesen, wie es scheint, noch nicht eingescheideten Irisfortsätzen, sind nicbt gemacht. Jedoch spricht sich derselbe an anderer Stelle der gleichen Arbeit bestimmt dahin aus, dass er überall, wo er Endothel erhalten fand, dasselbe in continuirlicher Schicht antraf.

Es ist aber darauf aufmerksam zu machen, dass eine Einscheidung von Seiten der Glasmembran und eine Endothelbekleidung nicht zwei sich deckende Begriffe sind, und dass Theile der Irisbalken, welche nicht, oder noch nicht eingescheidet sind, dennoch einen Endothelbelag haben können. - In der neuesten Arbeit von diesem Jahre, welche diese Verhältnisse behandelt, von Ar-

1) 1. C.

$\left.{ }^{2}\right)$ L. Koenigstein, Ueber die Endigung der Tunica Descemeti. Archiv f. Ophth. Bd. 25. III.

3) A. Angeluccl, Centralbl. f. med. Wiss. 1879. S. 417.

4) F. Heisrath, Ueber die Abflusswege des Humor aqueus etc. Archiv f. Ophth. Bd. 26. I. 
noldo Angelucci ${ }^{t}$ ), ist darauf Werth gelegt, dass bei der Entwickelung der vorderen Kammer zuerst das Endothel vorhanden ist, und später erst die sog. elastische Haut von aussen oder vorn her sich daran schliesst, oder am Endothel entlang wächst. Die innere Reihe von Irisfortsätzen, welche im weiteren Wachsthum mit ihren vorderen Spitzen der Membrana Descemeti begegnen, werden dann von dieser umwachsen; dies findet aber eben hinter dem schon vorher vorhanden gewesenen Endothelbelage statt. Die äusseren Reihen der Irisfortsätze haben nach Angelucci zu der Descemet'schen Haut gar keine Beziehungen.

Was nun die Vorderfläche der Iris betrifft, so wiederholt Iwanoff auch in Gräfe-Sä misch's Handbuch I. Seite 281 seine früher mit Rollet gemachten Angaben, dass zwar die Endothelzellen der vorderen Irisfläche nicht ganz genau mit denen der hinteren Hornhautwand übereinstimmen, dass sie aber als continuirliche Fortsetzung dieser anzusehen seien. - Vollkommen positiv sind ferner die Angaben Faber's ${ }^{2}$ ) und Michel's ${ }^{3}$ ). Beide sprechen sich auf Grund zahlreicher eigenen Untersuchungen und mit Berücksichtigung der entgegenstehenden Angaben der Literatur mit so voller Sicherherheit für die Existenz des continuirlicher Endothelbelages aus, dass die Zweifel v. Wecker's ${ }^{4}$ ) und Manz's ${ }^{5}$ ) dadurch wohl überwunden werden müssen.

Wenn nun alle aus diesen Räumen austretenden Stoffe diese Endothelschicht zuerst zu passiren haben, so scheint zwar nach den in Theil I gewonnenen Resultaten die Möglichkeit eines "offenen“" Zusammenbanges zwischen vorderer Kammer und. Ciliarvenen, auch bei continuirlichem Endothelbelage principiell nicht ausgeschlossen zu sein - aber nur in dem Sinne, dass Lymphbahnen die Communication zwischen Endothelialwand der vorderen Kammer und Endothelialwand der Blutgefässe vermitteln.

1) Angelucci, Ueber Entwicklung und Bau des vorderen Uvealtractus der Vertebraten. Arch. f. mikr. Anat. Bd. 19. II.

2) Faber, C., Der Bau der Iris des Menschen und der Wirbelthiere. Gekrönte Preisschrift. Leipzig $\mathbf{1 8 7 6 .}$

3) Michel, J., Ueber Iris und Iritis. Arch. f. Ophth. 27. Il. 1881. S. $174 \mathrm{ff}$.

4) v. Wecker, Gräfe-Sämisch Handb. IV. S. 486.

5) Manz, Ueber albinotische Menschenaugen. Archiv f. 0phth. Bd.24. IV. (Siehe S. 146.) 
Aus den bisher vorliegenden ziemlich zahlreichen Beobachtungen ergjebt sich, dass zwar im ganzen Bereiche der vorderen Kammer eine Resorption zwischen und in die Endothelzellen an hinterer Hornhautwand, Iriswinkel und Vorderfläche der Iris geschehen kann, dass aber die Weiterleitung aufgenommener Stoffe in transversaler Richtung durch die Membrana Descemeti hindurch nach der Hornhaut in den centralen Partien der letzteren unter normalen Verhältnissen nicht stattfinde, wohl aber an den Randpartien derselben, - und dass von da ab der ganze übrige Theil der Kammerwand sich sehr erheblich an der Resorption betheiligt. Das Nähere darüber lehren ausser den allbekannten Versuchen Leber's und Schwalbe's besonders die folgenden Angaben:

Brugs $\mathrm{ch}^{1}$ ) (Göttingen) erhielt nach Injection körnigen Farbstoffs in die vordere Kammer des lebenden Kaninchens an der hinteren Hornhautwand, sowie an der vorderen Irisfläche die Endothelzellen selbst, nicht nur deren Zwischenräume, deutlich mit Pigment erfüllt. Die stärkste Ablagerung von Farbstoff fand in der Gegend des Iriswinkels und auf der Iris statt. Ferner ergaben sich mit Pigment gefültte Zellen im Gewebe des Iriswinkels, zum Theil deutlich den Wänden der Scleralgefässe folgend, und bis weit in die Choroidea hinein, sowie in der ganzen Iris. Siehe seine Zeichnungen in v. Graefe's Archiv Bd. 23. Abth. III. Taf. VII. Figg. 1, 2, 3. Seine Figur 4 glaube ich im Sinne gefüllter Lymphbahnen, resp. anastomosirender Hornhautzellen deuten zu dürfen, welche in stärkeren Ausdehnungszuständen ein Aufliegen auf den Endothelzellen vortäuschen können, wovon ich mich oft überzeugt habe. Ich habe solche Figuren am ausgeschnittenen Bulbus durch Injection körnigen Farbstoffs in die vordere Kammer nach Anbringung eines vorderen Epithelverlustes (siehe später) ebenfalls erzielt und auch an der ausgeschnittenen Hornhaut, nachdem der Bulbus vorher kräftigem Drucke ausgesetzt gewesen.

Aus Deutschmann's ${ }^{2}$ ) (Göttingen) Versuchen geht hervor, dass für die Aufsaugung pathologischer Inbaltsmassen aus der vorderen Kammer am Wesentlichsten die Iris in Betracht komme.

1) Brugsch, l. c.

2) R. Deutschmann, Klinische und experimentelle Beiträge zur Resorption pathologischer Inhaltsmassen in der vorderen Augenkammer. v. Gräfe's Archiv. 24, II. 
Beide konnten nicht constatiren, dass Farbstoff in das Lumen von Blutgefässen eingedrungen sei.

Calberla ${ }^{1}$ ) (Bonn) und Heisrath ${ }^{2}$ ) (Königsberg), konnten das Eindringen körniger, resp. nicht diffusionsfähiger flüssiger Stoffe in das Lumen von Blutgefässen ihrer Angabe nach mit Sicherheit, insbesondere unter sicherem Ausschluss von Zerreissungen constatiren:

$\mathrm{Knies}^{3}$ ) hat am lebenden Kaninchen zwischen zwei Reiben von Endothelzellen in der Gegend des Hornhautrandes eine ringförmige Zone durch Blaufärbung dargestellt erhalten, welche die ganze Membrana Descemeti quer durchsetzte; er giebt auch an, dass bei Punction der vorderen Kammer eine grössere Sicherheit der Resultate herrschte, und betont ausdrücklich, dass sich die betreffende Stelle des Endothelbelages, wo der Streifen beginnt, durch Nichts von den übrigen Stellen der hinteren Hornhautwand unterschied. Auch Waldeyer hatte sich vergeblich nach Porenkanälchen in der Descemet'schen Haut umgesehen.

Unabhängig von Knies hat auch Leopold Weiss ${ }^{4}$ ) diesen Abflussweg mit gleicher Sicherheit constatirt. Nach der Zeichnung liegt bei ihm dieser Streifen etwas centraler als bei $\mathrm{Knies}$.

U1rich ${ }^{5}$ ) sah, wie ich wohl annehmen darf, das gleiche Bild, nur unter etwas abweichender Auffassung; er sah auch, wie Knies, öfters mebr als einen solchen Resorptionsstreifen, und giebt überhaupt dessen Lage als etwas wechselnd an.

Man kann aber, nach Anbringung eines vorderen Epithelverlustes, an jeder beliebigen Stelle der hinteren Hornhautwand solche Resorptionsstreifen hervorrufen, bei rollkommen unversebrter Endothelschicht.

Es ist, wie ich glaube, kaum notbwendig, nähere Mittheilungen hierüber erst zu motiviren, da ja vordere Epithelverluste unzählige Male und in den mannichfachsten Formen intra vitam Gegenstand augenärztlichen Interesses sind. - Wie ich glaube, muss ange-

1) Calberla, I. c. S. Th. I.

2) Heisrath, l. c.

3) M. Knies, Zur Lehre von den Flüssigkeitsströmungen im Iebenden Auge etc. Dieses Archiv Bd. 65. Taf. 20. Fig. 1 u. 2.

4) L. Weis, Ueber die Abllusswege der intraocularen Flüssigkeiten. v. Gräfe's Archiv 25. II. Taf. VII.

5) R. Ulrich, Ueber die Ernährung des Auges. v. Gräfe's Archiv 26. IIl. Taf. I. 
nommen werden, dass bei Entstehung eines vorderen Epithelverlustes an der Hornhaut, an der betreffenden Stelle eine Strömung aus der vorderen Kammer oder in dieselbe hervorgerufen wird, welche bei intacter Endothelschicht eine directe transversale Communication $z$ wischen vorderer Kammer und Hornhaut in bestimmter Zone herstellt.

Die in meiner früheren Abhandlung besprochenen Querschnitte waren nicht dazu bestimmt, eine Vorstellung zo verschaffen, auf welchen Wegen das Eisenchlorid, resp. das Berlinerblau durch die Membran hindurch zur Hornhaut gelange. Aber vereinzelte Querschnitte erbielt ich bei der damals angewandten Methode schon, welche eine Menge blauer Streifen mit Deutlichkeit erkennen liessen, die durch die ganze Membran hindurchreichten (Fig. 14). Durch eine Reibe von Versuchen gelang es, Bedingungen aufzufinden, welche zur constanten Erzielung ähnlicher Querschnittsbilder erfüllt werden mussten, und auch weitere, damit zusammenhängende Fragen befriedigend $\mathrm{zu}$ beantworten schienen.

An einem frisch ausgeschnittenen Bulbus injicire man von der Aequatorialgegend aus Eisenchloridlösung in die vordere Kammer. Darauf schneide man mit dem Rasirmesser am vorderen Hornhautepithel an beliebiger, z. B. centraler Stelle eine dünne Schicht ab, und tropfe auf diese Stelle dann die Lösung des Blutlaugensalzes in Zwischenpausen mehrere Male auf. Im Bereiche des Epitheldefectes bildet sich eine intensive Blaufürbung aus. Dann schneide man die Hornhaut aus, ziehe die hintere Wand in dünner Schicht $a b$, schneide die gefärbte Stelle aus, spüle sie kurz ab, und bringe sie in Glycerin unter Deckglas. Man constatirt dann, was man der Sicherheit wegen auch schon an der ganzen Hornhaut sich ansehen konnte, dass sich die entstandene Färbung bis in die Membrana Descemeti erstreckt, und zwar sieht man eine dunkelblaue Linie in der Membran verlaufen, welche dem Orte, und auch ungefähr der Form des Randes des an der Vorderfläche etablirten Epithelverlustes entspricht. Jedoch liegt die Linie immer etwas nach einwärts von jenem Rande. Nach aussen von dieser Linie ist immer sehr intensive, nach innen gewöhnlich sehr schwache Bläuung vorbanden; die letztere nimmt jedoch an vielen Präparaten an Intensität zu. Die intensive äussere Färbungszone stellt sich bei der Untersuchung als schräg absteigende Färbung der Hornhautgrundsubstanz, die 
innere schwache dagegen entweder als Färbungen im Bereiche der Endothelzellen, oder als ganz matte Färbung der Hornhautgrundsubstanz heraus (Fig. 15).

Die dunkle blaue Linie läuft meistens geschlossen in sich zurück, zeigt aber an vielen Stellen ein- und ausspringende Winkel, hat auch oft Lücken; oft sind auch nach innen oder aussen mehr Bruchstücke gleichartiger Linien vorbanden. Ferner entspricht ihr Verlauf nur an einzelnen Stellen den Zellenzwischenräumen; im Ganzen läuft sie scheinbar regellos mitten durch die Zellenfelder, meistens, wie es scheint, an der Basis der Zellen, und vorwiegend oft an den Kernen vorbei. Fügen wir bald, um das Flächenbild übersichtlich zu betrachten, noch hinzu, dass ganz eben so erscheinende blaue Linien, nur nicht in so geschlossener Form, auch innerbalb des intensiv gefärbten Theiles der Hornhaut nach allen Richtungen in kürzeren oder längeren Stücken durch einander laufen, und dass diese mit der ersterwähnten Linie hie und da anastomosiren.

Ferner sehen wir, dass überall, wo im Bereiche der Endothelzellen Färbungen stattgefunden haben, diese auf die uns bekannten Verzweigungen des Lymphröhrcbensystems ohne Schwierigkeit zurückzuführen sind. Die ersterwähnte geschlossene blaue Linie können wir ebenfalls mit Sicherheit in dieses System einfügen, in welchem ohne Weiteres eine solche ringförmige Leitung entstehen kann, wenn gerade in solcher Zone eine Ansaugung stattgefunden hat. Bei der Reichhaltigkeit der Verzweigungen bedarf dieser Punkt keiner besonderen Erläuterung mehr, da die Anschauung der Präparate diese Auffassung direct zu bestätigen geeignet ist.

Das Liniensystem, welches in der Hornhaut verläuft, zeigt einige beachtenswerthe Beziehungen. Zuerst erkennen wir, dass dasselbe an zahlreichen Stellen im Zwischenraum benachbarter Hornhautzellen verläuft. Sodann constatiren wir, dass an den Färbungsgrenzen des Gesammtbildes die am Weitesten vorgedrungene Färbung sich immer nur als gefärbter Rand der weissen Figuren präsentirt. - Es scheint hierin eine Analogie mit den Verhältnissen an den Endothelzellen zu liegen, wo ja für gewöhnlich auch nur die Zwischenräume, resp. die Ränder der Zellen für Färbungen leicht zugänglich sind, weil daselbst die Anfänge der Lymphbahnen zu suchen sind, während deren Fortsetzungen in das Gebiet der Zellen hinein sich nur unter besonderen Umständen darstellen lassen. 
An die markirten blauen Linien schliessen sich dann vielfach weitere Färbungen an, die bekannte Hornhautzeichnung bildend. In den weissen Stellen sehen wir oft mit Sicherheit Kerne, von der Form der Endothelzellenkerne; zuweilen liegen in grösseren weissen Stellen auch mehr Kerne, was darauf deutet, dass daselbst an mehreren benachbarten Zellen keine gefärbte Zwischengrenze markirt ist. Weiteres ist an dem beschriebenen Flächenpräparat nicht mit Sicherheit zu erkennen.

Der Querschnitt ${ }^{1}$ ) dieses Präparates zeigt an vielen Stellen das in Fig. 16 dargestellte klare Bild. Ein blauer, scharf markirter, schmaler Streifen durchsetzt senkrecht die ganze Membrana Descemeti und geht direct in gefärbte Hornhaut über. - An ganz frischen Präparaten sieht man den Streifen, an der Basis der Zellen angelangt, die in der Fig. 16 dargestellte Knickung nach dem Zellenzwischeuraum zu machen, und an der Oberfläche, entsprechend der Stelle eines kleinen Stoma, ausmünden. Beim Aufbewahren der Präparate verschwindet dieser oberste Theil der Färbung oft sehr rasch. - An der Basis der durchschnittenen Endothelzelle constatirt man das relative Verhältniss zu dem blauen Streifen, welches der Flächenansicht entspricht. Bei dem einen Präparat findet man demgemäss das obere Ende des Streifens gerade einem Zellenzwischenraum entsprechen, während dasselbe an anderen mehr nach dem Innern eines Zellenfeldes zustrebt. Hieraus erklärt sich wiederum das frühere Querschnittsbild Tafel VIII. Fig. 12. 1. c. Nochmals sei betont, dass diese Präparate an jeder beliebigen Stelle der hinteren Hornhautwand zu erzielen sind; das hier besprochene stammt aus den centralen Partien.

In Rücksicht darauf, dass ich an der Linsenkapsel ganz ähnliche Verhältnisse constatiren konnte, sowohl was das Epithel der Innenfläche und seine unmittelbare Unterlage, als auch, was die eben beschriebenen Querschnittsbilder betrifft, so konnte ich die Resultate an der Membrana Descemeti nicht als vereinzelte Erscheinung, sondern als Paradigma einer allgemeineren Einrichtung ansehen. Es erschien deshalb wünschenswerth, soweit wie möglich die Resorptionsbilder mit Structurverbältnissen der Membran in Ein-

1) $\mathrm{Zu}$ diesen Versuchen wurden der mächtigeren Dimensionen wegen vorzugsweise Ochsenaugen benutzt, welche auch den früheren Querschnittszeichnungen zu Grunde gelegen batten. 
klang zu bringen. - Die Eisenchloridpräparate scheinen in dieser Beziehung geeignet, die Ansicht derjenigen Autoren zu stätzen, welche überhaupt eine Structur, und insbesondere eine faserige für die Membrana Descemeti behauptet haben. Namentlich gelang es Tamamscheff ${ }^{1}$ ), die Membran durch Jod-Jodkaliumlösung in feine Fibrillen zu zerfällen, was mit der Ansicht von Brücke ${ }^{2}$ ) und Mensonides ${ }^{3}$ ), welche eine lamellöse Structur annehmen, sich vereinigen lässt, ähnlich wie bei der eigentlichen Hornbaut. Die Beobachtungen L. Löwe's über die Structur der Membrana Descemeti in den Wiener medic. Jahrbüchern 1875 sind mir nicht zugänglich gewesen.

Die bei den sog. elastischen Häuten leicht vorkommenden künstlichen Zeichnungen sind im Folgenden richtigt gewürdigt und ausgeschlossen worden. Es zeigt sich an einer grossen Zahl von Präparaten eine deutliche Längsstreifung, welche entweder parallel oder auch schräg zur Oberfläche verläuft, und welche auch von Ciaccio in ähnlicher Weise beschrieben wurde (Fig. $17 \mathrm{a}, \mathrm{b}$ ). Ferner sind an der Oberfläche des Querscbnitts kleine runde oder längliche Querschnittsfiguren einzelner Fasern zu constatiren. Die Formen dieser Figuren wechseln sichtlich von vertical bis zu schräg durchschnittenen Fasern in mannichfachen regelrechten Uebergängen $a b$, und sind immer so geordnet, dass sie den Durchschnitten ganzer Züge oder Schichten entsprechen (Fig. 18). - Sodann sieht man an den Schnittenden sehr häufig Zerfaserungen, und erkennt deutlich die Schnittenden der einzelnen Fasern, und zwar nicht nur an den Querschnittsenden, sondern auch an der Grenze zur eigentlichen Hornhaut, wenn gerade eine zufällige Trennung daselbst stattgefunden hat. - Endlich ist diese Grenze zur Hornhaut mitunter gar nicht in Form einer scharf markirten Linie vorhanden, sondern es vollzieht sich der Uebergang ganz allmählich, so dass sich sogar ein zart welliger Verlauf bis in die Membrana Descemeti hinein erstreckt.

Solche Bilder scheinen nur die Deutung zuzulassen, dass eine Kreuzung von Faserzügen in rechten und schiefen Winkeln und in einer grösseren Zahl über einander geschichteter Lagen anzunehmen

1) Tamain scheff, Centralblatt f. d. med. Wiss. 1869. No. 23.

2) Brücke, Anat. Beschreibung des menschl. Augapfels. Berlin 1847.

3) Mensanides, Nederlandsch Lancet. 2 Ser. IV Jaar. 1849. 
sei. Hiermit liessen sich auch alle vorkommenden Färbungen des Querschnittes, die manchmal in schrägen und wechselnden Richtungen verlaufen, eher in Uebereinstimmung bringen. Der blaue Streifen, welcher die Descemet'sche Membran durchsetzt, erstreckt sich an den frischen Präparaten für gewöhnlich continuirlich weiter durch die Hornhautschichten hindurch, nur wird hier die Färbung nach beiden seiten hin schneller diffus.

Macbt man nun durch die blaue Linie, wie sie vom Flächenpräparate beschrieben wurde, in der geschilderten senkrechten Richtung eine ganze Anzahl von Querschnitten binter einander, so ergiebt sich oft eine starke Schwankung in der Intensität der Färbung. Man trifft dabei Schnitte, an denen man im Vergleich zu den scharf gezeichneten Linien benachbarter Schnitte mit Sicherheit annehmen darf, dass die matte Färbung erst durch Diffusion dahin gelangt sei. Dies spricht dafür, dass der Farbstoff nicht an allen Stellen der Linie gleichmässig, sondern durch Zwischenräume getrennt, die Membran durchsetzt habe.

Der Querschnitt Fig. 16 liefert aber direct den Beweis, dass der Farbstoffstreifen an der Grenze zur Hornhaut zu einem Röbrchen in Beziehung tritt, welches an eine Hornhautzelle herangeht, und auf der anderen Seite dieser Hornhautzelle setzt sich ein gleichartiges Röhrchen weiter fort, indem es die Verbindung zu einer zweiten Hornhautzelle herstellt.

Aus Allem dürfte sich mit ziemlicher Sicherheit ergeben, dass wir die Farbstofflinie des Querschnittes in den Bereich der anastomosirenden Hornhautzellen hineinbeziehen müssen.

Wir haben hier also einen Fall gegeben, wo bei Setzung eines vorderen Epithelverlustes an beliebiger Stelle und auf bekannten Wegen eine Communication zwischen vorderer Kammer und dem Innern der Hornhaut direct durch die Descemet'sche Haut hindurch stattfindet, und haben auch hier keinen Grund für die Annahme besonderer Lymphgefässe finden können, welche sich als etwas von den anastomosirenden Hornhautzellen Unabhängiges auffassen liessen, vielmehr mussten wir die Leitungswege wieder in nerhalb jenes Systems von $\mathrm{Z}$ ellen suchen, in welchem auch körperliche Gebilde transportirt werden können. 
Es erübrigt noch, eine kurze Mittheilung zu machen über

$$
\text { Die Resultate der Einstichsinjection. }
$$

Hierzu wurde vorzugsweise Cardol, das Extract der AnacardiumNüsse, benutzt, und die Injection vom Rande der Hornhaut aus vorgenommen. - Es stellte sich heraus, dass die Füllung sow ohl der anastomosirenden Zellen an den Knotenpunkten der Endothelzellen, als auch der letzteren selbst fast regelmässig vom Innern der Hornhaut aus gelingt. Für das vordere Epithel sind die entsprechenden Erfolge schon von Leber und Raehlmann bekannt gemacht worden; nur wurde dort auf die Zellen selbst noch nicht in solchem Maasse geachtet (siehe die Einleitung l. c.). - Fig. 19 giebt eines der zahlreichen dabei zu beobachtenden Bilder wieder, welche man nicht lange aufbewahren kann, weil sich das 0 el nachträglich anders vertheilt, und auch an vielen Stellen austritt, obwohl auch hierbei nach Auftropfen von Eisenchlorid das Abziehen der hinteren Hornhautwand mit leidlicher Erhaltung des Bildes gelingt. - Ferner beobachtet man auch hierbei wieder isolirte, mit Oel gefüllte Röbrchen, welche, wie es scheint, in Folge der stärkeren Cohäsion des eingedrungenen Oels, hier auf grössere Strecken zusammenhalten, als nach den früheren Methoden.

Es ist noch hervorzuheben, dass Zellenzwischenräume, welche sich in der Form der Fig. 19 a präsentiren, nach Oelinjection die Form $19 \mathrm{~b}$ annehmen können, wie aus den mannichfachen Uebergängen dieser Art hervorgeht. Die Form $19 \mathrm{a}$ ist also nichi als eine Reihe benachbarter Oeffnungen, sondern als ein perlschnurartig verlaufendes längsgerichtetes Röhrchen anzusehen. Wir haben deshalb auf S. $340 \mathrm{ff}$. in der früheren Darstellung (l. c.) eine Correctur in diesem Sinne vorzunehmen; auch dürfen wir vermuthen, dass die dortige Auffassung der Stachelzellen (Fig. 3. Taf. VII. l. c.) durch die hier beschriebenen Verhältnisse eine erhebliche Aenderung zu erfahren hat, indem die Zellenfortsätze dort mit der Wand von Röhrchen identisch sein dürften.

Was die oberflächlichsten Zellengrenzen betrifft, so geht sowohl aus den Injectionsbildern wie auch aus den früher beschriebeven Untersuchungsmethoden hervor, dass dieselben von der Verlaufsweise und von dem Füllungsgrade der im Grunde der Zellenzwischenräume verlaufenden Röhrchen abbängig sịnd, Verlaufen dịe 
Röbrchen gestreckt, wie Fig. 20 es andeutet, so entspricht diesem Verbalten die streng polygonale oder runde Form der Zellen. Sind die Röhrchen aber geschlängelt, und ausgebuchtet, so bilden auch die oberflächlichsten Zellengrenzen entsprechende Linien.

Haben die Röhrchen einen gewissen Füllungszustand überschritten, so stossen die Zellen an der äussersten Oberfläche nicht mehr mit lineären Grenzen an einander, sondern erscheinen von einander abstehend, entweder nur an einzelnen rundlichen oder länglichen Stellen, oder an einer ganzen Seite entlang, oder rings herum.

Beim Auftropfen von Flüssigkeiten auf die frische Membran scheint der Concentrationsgrad zu bedingen, wie sich Röhrchen und Kernmembranen mit ihren Mündungen dagegen verhalten, und davon scheint wiederum das schon früher (l. c.) geschilderte verschiedenartige Bild abhängig zu sein.

\section{Erklärung der Abbildungen. Tafel II - IV.}

Fig. 1. Isolirte Lymphröhrchen der Membrana Descemeti mit und ohne Mündung.

Fig. 2. Darstellung der Lymphröhrchen; danach die hintere Hornhautwand abgezogen. Knotenpunkte der Verzweigungen sind dabei verloren gegangen.

Fig. 3. a Wahre Stomata an den Knotenpunkten. b Variable Grösse derselben, und oft kernartige Figuren an deren Stelle. c Ansatz der Röhrchen an die Stomata. In den Zellenzwischenräumen ebenfalls solche Röhrchen. d Weitere Illustration der Röhrchen in den Zellenzwischenräumen.

Fig. 4. Endothelzellen, künstlich in Pigmentzellen umgewandelt.

Fig. 5. Verbindungen von Lymphröhrchen za Kernmembranen innerhalb von Zellen.

Fig. 6. a Verfolg von Lymphröhrchen durch Zellen hindurch nach dem Scbema der Fig. 5. b Partielle Zellenfärbung, aus ähnlichem Schema zu erklären, und nicbt mit Kernen zu verwechseln.

Fig. 7. Pigmentzellen des Hornhautrandes. Entstehung derselben.

Fig. 8. Resorption des körnigen Pigmentes aus der vorderen Kammer.

Fig. 9. a b c Beziehungen der Kerne und ihrer Membranen zu den Lymphröhrchen.

Fig. 10. L.ymphröhrchen als Fortsätze der Hornhautzellen.

Fig. 11. Hornhautzellen, resp. die analogen Gebilde in der Membrana Descemeti, gelegen an den Knotenpunkten der Endothelzellen. An thnen sieht man Kerne mit gefüllter Membran uঘd Fortsätzen. - Künstliche Umwandlung derselben in Pigmentzellen durch chinesische Tusche.

Fig. 12. a Dieselben Zellen, durch Berlinerblan positiv dargestellt, mit nur theilweiser Erhaltung beim Abziehen der hinteren Hornhautwand. b Dieselben isolirt mit anhängenden Röbrchen. c Lymphröhrchen, scharf abgeschnitten endigend, weil die Zellen, von denen sie ausgingen, sammt Kernmembran ausgefallen sind. 
Fig. 13. Hornhautzellen mit ron ihnen ausgehenden Lymphröhrchen.

Fig. 14. Resorptionsstreifen durch die Membrana Descemeti hindurch, bei unversehrtem Endothel.

Fig. 15. Anastomosen von Lymphröhrchen in der Membrana Descemeti, entstanden bei vorderem Epithelverlust.

Fig. 16. Querschnittsbild dazu.

Fig. 17. a Längsstreifung, b Schrägstreifung des Querschnitts der Membrana Descemeti.

Fig. 18. Faserquerschnitte der Membrana Descemeti.

Fig. 19. Oelinjection des Lymphröhrchennetzes der-Membrana Descemeti von der Hornhaut aus erzielt.

Fig. 19. a b lllustration der perischnurartigen Röhrchen in den Zellenzwischenräumen.

Fig. 20. Illustration der Abhängigkeit der oberflächlichsten Zellengrenzen von der Verlaufsweise der in den Zwischenräumen verlaufenden Röhrchen.

\title{
VII.
}

\section{Kleinere Mittheilungen.}

\author{
1. \\ Ueber den 0ssificationsprozess. \\ Von Dr. Julius Kaczander in Miskolcz (Ungarn). \\ (Hierzu Taf. V. A. Fig. 1-7.)
}

Der Talus menschlicher Embryonen war das Object meiner Untersuchungen. Die Leichtigkeit der Vorbereitung desselben zur histologischen Untersuchung, resp. die Möglichlzeit, mit einem Knochenkerne von ziemlicher Grösse versehene Tali durch 1 procentige Chromsäure in 24 Stunden zu entkalken, ferner der Umstand, dass seine Verknöcherung sehr langsam erfolgt, ermöglicht sehr bequem die Untersuchung aller Stadien derselben. Wie oben bemerkt, entzog ich die Kalksalze durch 1 procentige Chromsäure, welche unter allen mir bekannten Mitteln schnell am schonendsten uns diesen Zweck erreichen lässt, dann legte ich den Knochen auf 4-5 Stunden in gewöhnlichen Alkohol, nach welcher Zeit ganz gute Schnitte gemacht werden können. Zeichen von Zerstörang sind an den, auf diese Weise präparirten Objecten nicht zu finden, während längere Zeit in Alkohol gelegene Objecte nach meiner Meinung unbrauchbar sind, weil dadurch z. B. die dem Verknöcherungscentrum zunächst gelegenen grossen Knorpelzellen fast vollständig verändert werden und Trugbilder entstehen, wie ich sie später schildern werde.

Es lassen sich an einem ossificirenden Talus folgende Schichten unterscheiden: 1) eine sehr dünne Perichondriumschicht, 2) ein grosses Territorium von verschieden grossen Knorpelzellen, weiche rund-, spindel-, keulen-, halbmondförmig sind, und 
Tirchom's Archiv. Bd. LXXXVU.

A.

Taf. V.
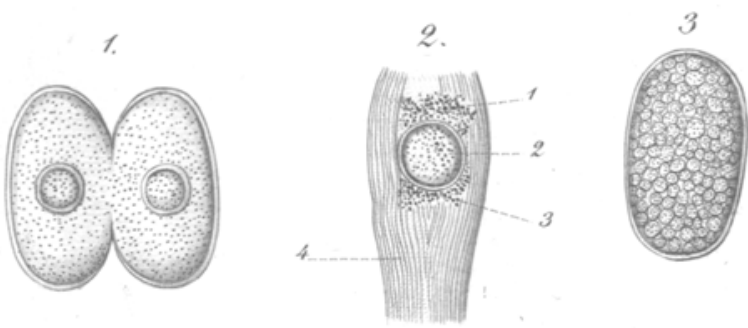

4 .

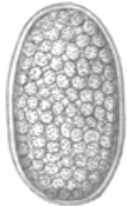

G.
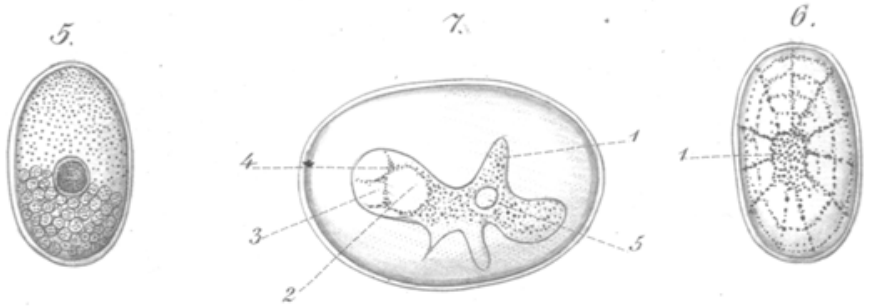

$B$.

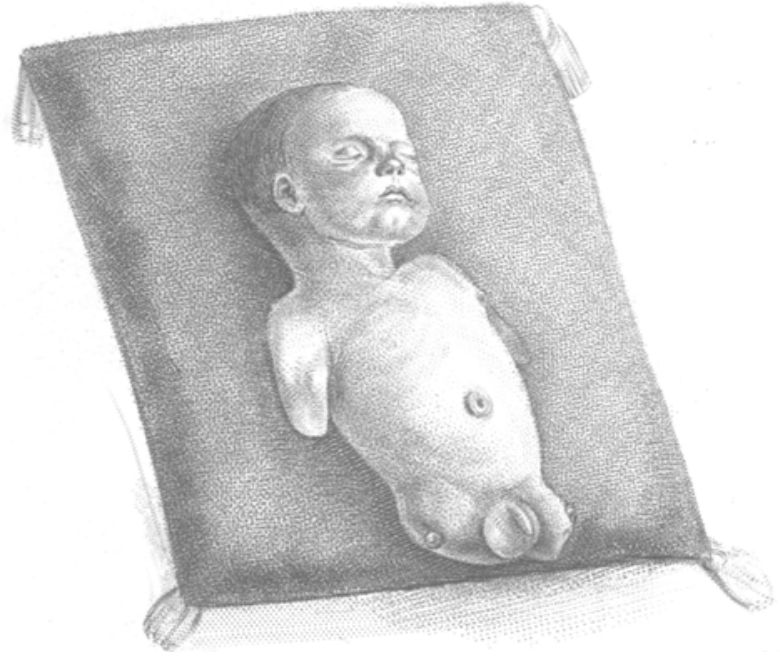

W. Grohnasn ôc. 